Hydrol. Earth Syst. Sci., 17, 1693-1703, 2013

www.hydrol-earth-syst-sci.net/17/1693/2013/

doi:10.5194/hess-17-1693-2013

(C) Author(s) 2013. CC Attribution 3.0 License.

\title{
Anomalous frequency characteristics of groundwater level before major earthquakes in Taiwan
}

\author{
C.-H. Chen ${ }^{1}$, C.-H. Wang ${ }^{1}$, S. Wen ${ }^{2}$, T.-K. Yeh ${ }^{3}$, C.-H. Lin ${ }^{1}$, J.-Y. Liu ${ }^{4,5}$, H.-Y. Yen ${ }^{6}$, C. Lin ${ }^{7}$, R.-J. Rau ${ }^{7}$, and \\ T.-W. Lin $^{8}$ \\ ${ }^{1}$ Institute of Earth Sciences, Academia Sinica, Taipei 115, Taiwan \\ ${ }^{2}$ National Center for Research on Earthquake Engineering, Taipei 106, Taiwan \\ ${ }^{3}$ Department of Real Estate and Built Environment, National Taipei University, New Taipei City 237, Taiwan \\ ${ }^{4}$ Institute of Space Science, National Central University, Jhongli 320, Taiwan \\ ${ }^{5}$ Center for Space and Remote Sensing Research, National Central University, Jhongli 320, Taiwan \\ ${ }^{6}$ Institute of Geophysics, National Central University, Jhongli 320, Taiwan \\ ${ }^{7}$ Department of Earth Sciences, National Cheng Kung University, Tainan, Taiwan \\ ${ }^{8}$ Seismological Center, Central Weather Bureau, Taipei 100, Taiwan \\ Correspondence to: C.-H. Chen (nononochchen@gmail.com)
}

Received: 12 April 2012 - Published in Hydrol. Earth Syst. Sci. Discuss.: 4 June 2012

Revised: 25 March 2013 - Accepted: 28 March 2013 - Published: 2 May 2013

\begin{abstract}
Unusual decreases of water levels were consistently observed in $78 \%(=42 / 54)$ of wells in the Choshuichi Alluvial Fan of central Taiwan about 250 days before the Chi-Chi earthquake ( $M=7.6$ on 20 September 1999) while possible factors of barometric pressure, earth tides, precipitation as well as artificial pumping were removed. Variations in groundwater levels measured on anomalous wells from $1 \mathrm{Au}-$ gust 1997 to 19 September 1999, which covers the 250 day unusual decreases, were transferred into the frequency domain to unveil frequency characteristics associated with the Chi-Chi earthquake. Analytical results show that amplitudes at the frequency band between $0.02 \mathrm{day}^{-1}$ and $0.04 \mathrm{day}^{-1}$ generally maintained at the low stage and were apparently enhanced a few weeks before the Chi-Chi earthquake. Variations of amplitude at this particular frequency band were further examined along with other Taiwan earthquakes $(M>6)$ from 1 August 1997 to 31 December 2009. Features of the enhanced amplitudes at the frequency band are consistently observed prior to the other two earthquakes (the Rei-Li and Ming-Jian earthquakes) during the $12.5 \mathrm{yr}$ study period. In addition, surface displacements recorded from GPS, which provides insights into understanding stress status in subsurface during the Chi-Chi earthquake, are also inspected. The result confirms that abnormal rise and fall changes in
\end{abstract}

groundwater level yield an agreement with forward and backward surface displacements around the epicentre prior to the Chi-Chi earthquake.

\section{Introduction}

Taiwan is an island located on the western margin of the Pacific Ocean with about $400 \mathrm{~km}$ in length and $150 \mathrm{~km}$ in width (Fig. 1). The convergent plate interaction between the Philippine Sea plate and the Eurasia plate has raised Taiwan and formed the central mountain with an altitude up to about $3952 \mathrm{~m}$ since around 6 million years ago (Ho, 1988). Annual precipitation in Taiwan is about $2500 \mathrm{~mm}$ on average based on the long-term records of Water Resources Agency (WRA, 2010), but rainfall is mainly concentrated in the wet season (May to October, about $78 \%$ of the annual total; also see Fig. 2) due to high contributions from Meiyu and typhoons. Rainfall retention for effective water resource management is very important in Taiwan because uneven distribution of precipitation is very prominent both in temporal and spatial modes. When water consumption is rapidly increased by population growth and economic development after 1980, a great quantity of groundwater has been used to make up 


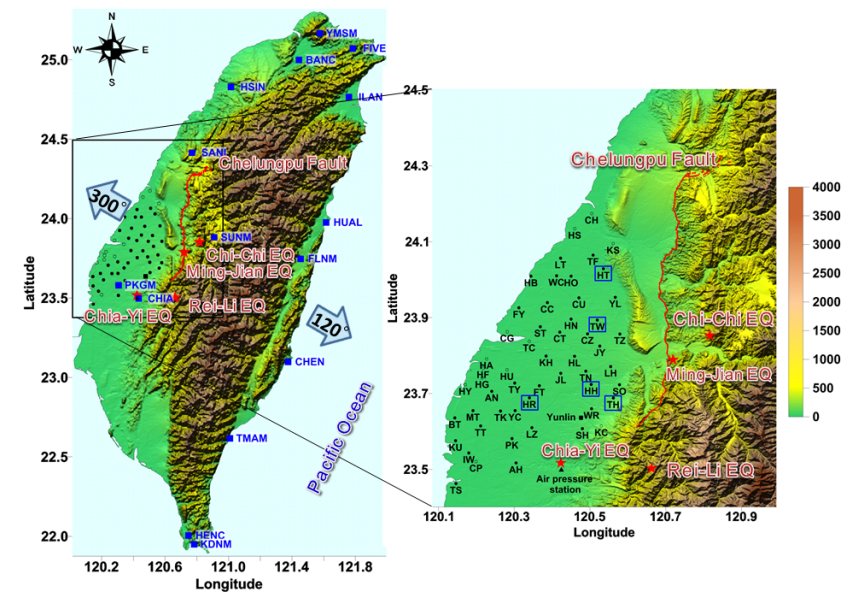

Fig. 1. Locations of 4 earthquakes, 54 groundwater wells and 15 GPS stations in Taiwan. Earthquakes and stations lies on topography of Taiwan. The red lines and stars denote the Chelungpu fault and distinct earthquake epicentres, respectively. The solid and open circles present groundwater levels with and without unusual level changes before the Chi-Chi earthquake, respectively. Air pressure (black triangle) and precipitation (black rectangle) are measured at stations located in the southern part of the study area. Meanwhile, the open (solid) blue rectangles denote locations of the well (GPS) stations in which the data presented in this study.

the insufficiency of surface water. Consequently, land subsidence happened following rapid depletion of groundwater resources in the western and southwestern regions of Taiwan from the past decades, due to excessive extraction and slow recharge (Liu and Huang, 2002; WRA, 2001; Wang, 2007).

The most notorious land subsidence region with an active subsiding area of over $600 \mathrm{~km}^{2}$ and a maximum subsiding rate up to $10 \mathrm{~cm} \mathrm{yr}^{-1}$ is located at the Choshuichi Alluvial Fan of central Taiwan (Chen et al., 2010a). To effectively utilise groundwater resource and control (or mitigate) land subsidence along coastal areas, where pumping is intensive and recharge is very slow (Liu and Huang, 2002; WRA, 2001), 54 evenly distributed hydrologic stations that record hourly changes in water levels using piezometers were installed at depths ranged from $24 \mathrm{~m}$ to $306 \mathrm{~m}$ in the Choshuichi Alluvial Fan during 1992-1997 (Fig. 1 and Table 1; Hsu, 1998). A complete list of monitoring wells can be found in the original Water Resource Bureau (WRB) report (WRB, 1999). The Choshuichi Alluvial Fan, with an area of about $1800 \mathrm{~km}^{2}$, can be divided into three aquifers for a depth of $250 \mathrm{~m}$ according to hydrogeological surveys in subsurface (Chen and Yuan, 1999; WRB, 1999). Each station may have one to five screens situated in different wells for fully observing groundwater level changes from shallow to deep aquifers.

The convergent plate interaction also causes many earthquakes in Taiwan (Fig. 1). From 1 August 1997 to 31 December 2009, 4 strong earthquakes $(M>6)$ (Table 2) occurred nearby the Choshuichi Alluvial Fan. The most prominent event among them is the Chi-Chi earthquake $(M=7.6)$

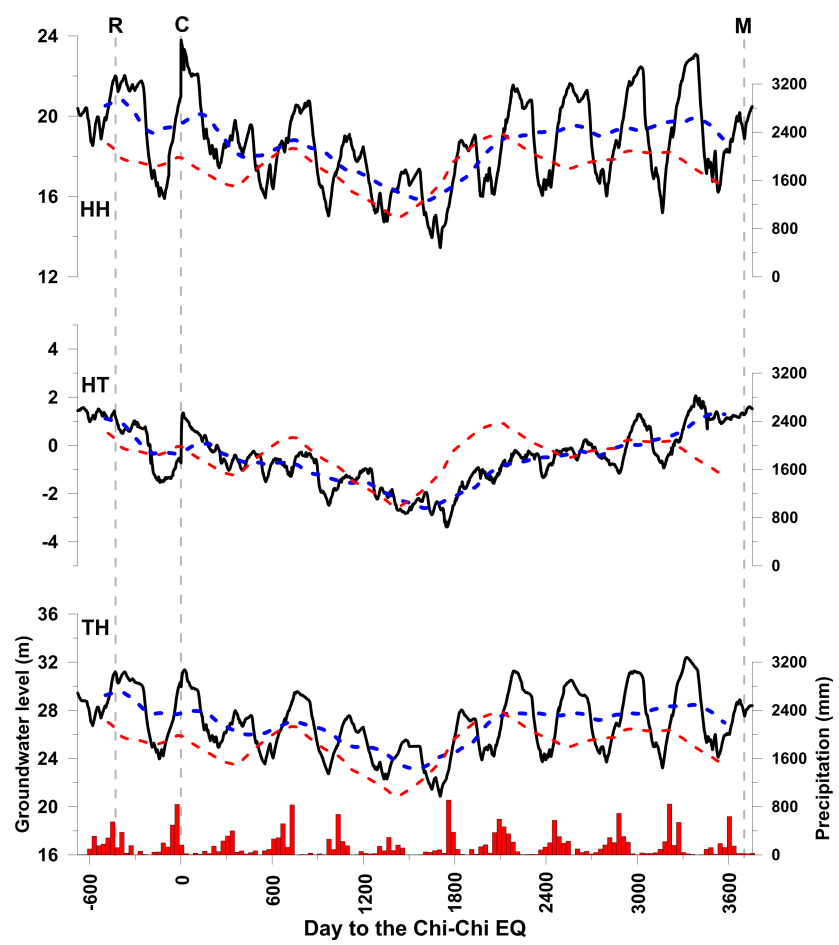

Fig. 2. Variations in groundwater levels at $\mathrm{HH}, \mathrm{HT}$ and TH stations from 1 August 1997 to 31 December 2009. The blue and red dash lines show variations in groundwater levels and precipitations on the $1 \mathrm{yr}$ running average. The vertical dash lines indicate occurrence dates of the R, C and M earthquakes.

on 20 September 1999 (Ma et al., 1999), which was the most destructive earthquake in the 20th century in Taiwan. This event severely destroyed more than one hundred thousand buildings and brought a casualty of about 2500 people (Yen et al., 2004). Groundwater levels in monitoring wells of the Choshuichi Alluvial Fan apparently recorded intense co-seismic changes caused by the Chi-Chi earthquake that has been widely reported (Wang et al., 2001; Wang et al., 2005). These co-seismic changes in groundwater levels took about 250 days to return to the normal state (also see Fig. 3). Since groundwater levels are changed while pressure in the shallow crust near the wells is intensified by strong earthquakes, they could be considered as a pressure indicator scrupulously response to stress changes. In this regard, groundwater level changes are not limited to co-seismic ones; signals before strong earthquakes are more valuable in terms of earthquake hazard prevention. In reality, variations of groundwater level are affected by barometric pressure, Earth's tides and other factors (Bredehoeft, 1976; Chen et al., 2010b; Chia et al., 2001; Igarashi and Wakita, 1991, 1995; Kingsley et al., 2001; Quilty and Roeloffs, 1997; Roeloffs, 1988, 1998; Narasimhan et al., 1984; Scholz et al., 1973; Van Der Kamp and Gale, 1983; Wang et al., 2001; Wang and Manga, 2010). Anomalous variations of groundwater level response to earthquakes are generally considered as 
Table 1. Locations and observation aquifers of the Choshuichi Alluvial Fan used in this study.

\begin{tabular}{|c|c|c|c|c|c|c|c|}
\hline Station & code & Long. & Lat. & Aquifer 1 & Aquifer 2 & Aquifer 3 & $\begin{array}{l}\text { Screen } \\
\text { depth }(\mathrm{m})\end{array}$ \\
\hline Anho & $\mathrm{AH}$ & 120.3045 & 23.5166 & $\mathrm{O}$ & $\mathrm{O}$ & $\mathrm{O}$ & $260-278$ \\
\hline Annan & $\mathrm{AN}$ & 120.2407 & 23.7058 & & $\mathrm{O}$ & $\mathrm{O}$ & 159-195 \\
\hline Chaochia & $\mathrm{CC}$ & 120.3872 & 23.9393 & & $\mathrm{O}$ & $\mathrm{O}$ & 180-198 \\
\hline Chiulung & $\mathrm{JL}$ & 120.4229 & 23.7529 & $\mathrm{O}$ & $\mathrm{O}$ & $\mathrm{O}$ & 179-191 \\
\hline Chiungpu & $\mathrm{CP}$ & 120.1992 & 23.5202 & & $\mathrm{O}$ & & \\
\hline Chuanhsin & $\mathrm{CH}$ & 120.5043 & 24.1738 & $\mathrm{O}$ & $\mathrm{O}$ & $\mathrm{O}$ & 183-192 \\
\hline Chutang & $\mathrm{CT}$ & 120.4202 & 23.8617 & $\mathrm{O}$ & $\mathrm{O}$ & & \\
\hline Fangtsao & FT & 120.3659 & 23.7202 & $\mathrm{O}$ & $\mathrm{O}$ & & \\
\hline Fangyuan & FY & 120.3123 & 23.9256 & & $\mathrm{O}$ & $\mathrm{O}$ & $187-205$ \\
\hline Haifeng & $\mathrm{HF}$ & 120.2178 & 23.7667 & & $\mathrm{O}$ & $\mathrm{O}$ & $166-178$ \\
\hline Haiyuan & HY & 120.1709 & 23.7226 & $\mathrm{O}$ & $\mathrm{O}$ & $\mathrm{O}$ & $160-196$ \\
\hline Hanbao & $\mathrm{HB}$ & 120.3442 & 24.0088 & & $\mathrm{O}$ & $\mathrm{O}$ & 173-197 \\
\hline Haoshiu & $\mathrm{HO}$ & 120.4501 & 24.0087 & & $\mathrm{O}$ & $\mathrm{O}$ & 174-204 \\
\hline Hofeng & $\mathrm{HG}$ & 120.2153 & 23.7409 & & $\mathrm{O}$ & $\mathrm{O}$ & $202-220$ \\
\hline Hohsin & $\mathrm{HN}$ & 120.4500 & 23.8959 & $\mathrm{O}$ & & $\mathrm{O}$ & $197-227$ \\
\hline Honglung & HR & 120.3399 & 23.6884 & $\mathrm{O}$ & & $\mathrm{O}$ & $209-212$ \\
\hline Hou-An & HA & 120.2267 & 23.7910 & & $\mathrm{O}$ & & \\
\hline Hsiantien & ST & 120.3689 & 23.8757 & $\mathrm{O}$ & & $\mathrm{O}$ & 194-218 \\
\hline Hsichou & $\mathrm{CZ}$ & 120.4931 & 23.8569 & $\mathrm{O}$ & $\mathrm{O}$ & & \\
\hline Hsienhsi & HS & 120.4595 & 24.1340 & $\mathrm{O}$ & $\mathrm{O}$ & $\mathrm{O}$ & 158-194 \\
\hline Hsihu & $\mathrm{CU}$ & 120.4708 & 23.9517 & & $\mathrm{O}$ & $\mathrm{O}$ & $176-200$ \\
\hline Hsikang & $\mathrm{CG}$ & 120.2813 & 23.8625 & $\mathrm{O}$ & $\mathrm{O}$ & $\mathrm{O}$ & $263-275$ \\
\hline Hsilo & HL & 120.4592 & 23.7977 & $\mathrm{O}$ & $\mathrm{O}$ & & \\
\hline Hsinhua & $\mathrm{HU}$ & 120.2808 & 23.7620 & & $\mathrm{O}$ & $\mathrm{O}$ & 185-197 \\
\hline Huatang & $\mathrm{HT}$ & 120.5352 & 24.0285 & $\mathrm{O}$ & $\mathrm{O}$ & $\mathrm{O}$ & 264-294 \\
\hline Huhsi & $\mathrm{HH}$ & 120.5030 & 23.7240 & $\mathrm{O}$ & $\mathrm{O}$ & $\mathrm{O}$ & $282-294$ \\
\hline I-wu & IW & 120.1802 & 23.5431 & $\mathrm{O}$ & $\mathrm{O}$ & $\mathrm{O}$ & $200-215$ \\
\hline Kanchiao & $\mathrm{KC}$ & 120.5298 & 23.6142 & $\mathrm{O}$ & $\mathrm{O}$ & & \\
\hline Kanghou & $\mathrm{KU}$ & 120.3839 & 23.7983 & & $\mathrm{O}$ & $\mathrm{O}$ & $195-210$ \\
\hline Kanyuan & JY & 120.5255 & 23.8248 & $\mathrm{O}$ & $\mathrm{O}$ & & \\
\hline Kinghu & $\mathrm{KU}$ & 120.1452 & 23.5751 & $\mathrm{O}$ & $\mathrm{O}$ & & \\
\hline Kuoshen & $\mathrm{KS}$ & 120.5610 & 24.0945 & $\mathrm{O}$ & $\mathrm{O}$ & $\mathrm{O}$ & $197-227$ \\
\hline Liuho & $\mathrm{LH}$ & 120.5544 & 23.7708 & $\mathrm{O}$ & $\mathrm{O}$ & & \\
\hline Lochin & LT & 120.4220 & 24.0562 & $\mathrm{O}$ & $\mathrm{O}$ & $\mathrm{O}$ & 180-198 \\
\hline Lungtze & $\mathrm{LZ}$ & 120.3467 & 23.6095 & & $\mathrm{O}$ & & \\
\hline Minte & MT & 120.1911 & 23.6547 & $\mathrm{O}$ & $\mathrm{O}$ & $\mathrm{O}$ & $198-216$ \\
\hline Paotze & $\mathrm{BT}$ & 120.1434 & 23.6353 & $\mathrm{O}$ & $\mathrm{O}$ & $\mathrm{O}$ & 176-206 \\
\hline Peikang & PK & 120.2938 & 23.5807 & & $\mathrm{O}$ & $\mathrm{O}$ & $162-180$ \\
\hline Sanho & $\mathrm{SH}$ & 120.4798 & 23.6070 & $\mathrm{O}$ & $\mathrm{O}$ & & \\
\hline Shiliu & SO & 120.5777 & 23.7225 & $\mathrm{O}$ & $\mathrm{O}$ & & \\
\hline Tanchien & $\mathrm{TC}$ & 120.3394 & 23.8374 & $\mathrm{O}$ & $\mathrm{O}$ & & \\
\hline Tienchung & $\mathrm{TZ}$ & 120.5787 & 23.8564 & $\mathrm{O}$ & $\mathrm{O}$ & & \\
\hline Tienwei & $\mathrm{TW}$ & 120.5192 & 23.8932 & $\mathrm{O}$ & & $\mathrm{O}$ & $210-240$ \\
\hline Tienyang & TY & 120.3009 & 23.7272 & $\mathrm{O}$ & $\mathrm{O}$ & $\mathrm{O}$ & $262-274$ \\
\hline Tsaitso & TT & 120.2111 & 23.6141 & $\mathrm{O}$ & $\mathrm{O}$ & & \\
\hline Tungfang & $\mathrm{TF}$ & 120.5078 & 24.0646 & & $\mathrm{O}$ & $\mathrm{O}$ & $162-174$ \\
\hline Tungho & $\mathrm{TH}$ & 120.5612 & 23.6877 & $\mathrm{O}$ & $\mathrm{O}$ & $\mathrm{O}$ & $222-252$ \\
\hline Tungkuang & TK & 120.2639 & 23.6537 & $\mathrm{O}$ & $\mathrm{O}$ & $\mathrm{O}$ & $166-175$ \\
\hline Tungshi & $\mathrm{TS}$ & 120.1464 & 23.4622 & & $\mathrm{O}$ & $\mathrm{O}$ & $228-237$ \\
\hline Tzetung & $\mathrm{TN}$ & 120.4887 & 23.7586 & $\mathrm{O}$ & $\mathrm{O}$ & & \\
\hline Wenchang & WC & 120.4114 & 24.0100 & $\mathrm{O}$ & $\mathrm{O}$ & $\mathrm{O}$ & 186-204 \\
\hline Wentso & WR & 120.5040 & 23.6596 & $\mathrm{O}$ & $\mathrm{O}$ & & \\
\hline Yuanchang & $\mathrm{YC}$ & 120.3019 & 23.6547 & & $\mathrm{O}$ & & \\
\hline Yuanlin & YL & 120.5666 & 23.9534 & $\mathrm{O}$ & $\mathrm{O}$ & $\mathrm{O}$ & $134-140$ \\
\hline
\end{tabular}




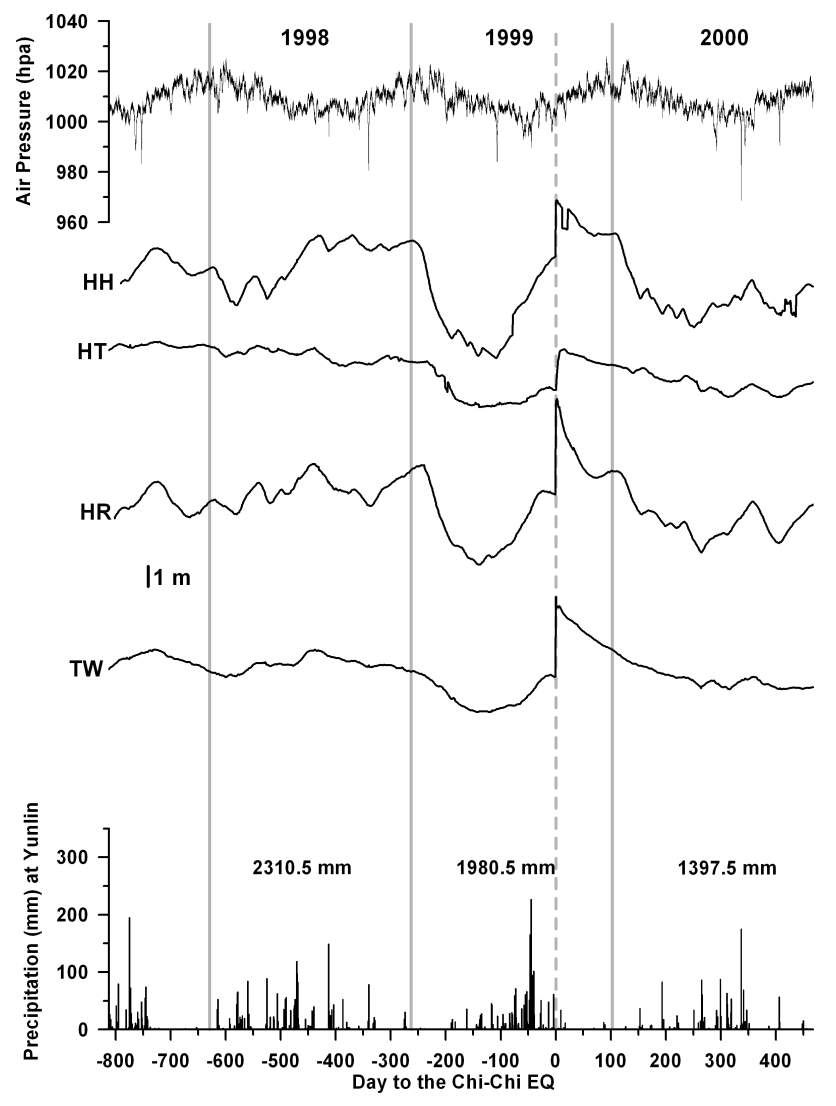

Fig. 3. Variations of air pressure, groundwater level at HH, HT, HR and TW sites as well as annual precipitations about 800 days before and 450 days (1 August 1997 to 31 December 2000) after the ChiChi earthquake.

meaningful (Brodsky et al., 2003; Igarashi and Wakita, 1991; Wang and Manga, 2010) while aforementioned factors can be effectively ruled out.

In this study, effects of the barometric pressure and Earth's tide on groundwater levels at 54 monitoring wells in the Choshuichi Alluvial Fan are mitigated first to examine any unusual variation associated with the Chi-Chi earthquake in the normally temporal domain. Notably, timeseries water levels in the period of $2.5 \mathrm{yr}$ right before the Chi-Chi earthquake are utilised to reveal frequency characteristics associated with the Chi-Chi earthquake via the Hilbert-Huang Transform (HHT) (Huang et al., 1998, 2003; Huang and $\mathrm{Wu}, 2008$ ) and retrieve suspect signals buried in the temporal domain. After the earthquake-related frequency band has been determined from records before the Chi-Chi earthquake, amplitudes at the particular frequency band, which have deduced from $12.5 \mathrm{yr}$ data from $1 \mathrm{Au}-$ gust 1997 to 31 December 2009 in groundwater stations of Huhsi (HH), Huatang (HT) and Tungho (TH), are further examined to check whether the identified anomalous amplitude can be repeatedly observed for other two major earthquakes (i.e., the Rei-Li and Ming-Jian earthquakes; details see Table 2). In addition, stress variations deduced by the surface displacements from the GPS (Global Positioning System) data are compared with abnormal changes in groundwater level during the Chi-Chi earthquake to examine possible physical mechanisms.

\section{Hilbert-Huang transform}

In general, time-series data are transferred from the temporal domain into the frequency domain using either the Fourier transform (Bracewell, 2000) or wavelet transform (Daubechies, 1990), based on the assumption of signal linearity. When four earthquakes, which occurred near the Choshuichi Alluvial Fan between 1 August 1997 and 31 December 2009, are taken into reconsideration, the intervals of these events are quite different. Three earthquakes (i.e., the Rei-Li (R), Chi-Chi (C) and Chia-Yi earthquakes) occurred before 2000 and the last (i.e., the Ming-Jian (M) earthquake) occurred at the end of 2009 (Table 2). The HilbertHuang transform (HHT), which can adapt nonlinear and nonstationary signals (Huang et al., 1998), is used to extract nonlinear earthquake-related anomalies from groundwater levels in this work.

HHT is comprised of the Empirical Mode Decomposition (EMD) and Hilbert spectral analysis (Huang et al., 1998). In the temporal domain, the data are decomposed into a series of components, which are termed Intrinsic Mode Functions (IMFs), using the Sifting process of EMD (details in Huang et al., 1998). In the Sifting process, the first step is to find entire local maxima and minima of the analysed data and connect them using the cubic spline method as the upper and lower envelopes, respectively. The difference between the analysed data and the average of the upper and lower envelopes is computed and is repeatedly substituted for the analysed data in the previous Sifting process. The Sifting process is temporally stopped when an average of the difference is less than $10^{-3} \mathrm{~m}$. In this point, the difference is determined as $\mathrm{IMF}_{1}$ and subtracted from the analysed data accordingly.

The subtracted data replace the analysed data to obtain subsequent IMFs by using the same Sifting process again. The Sifting process is consequently stopped, while the upper and lower envelopes cannot be constructed by enough quantities of the local maxima and minima. All of the derived IMFs are transferred into the frequency domain using the Hilbert transform one by one. Thus, IMFs can be obtained from decomposed time-series data regarding groundwater levels at each hydrologic station. After the process, the instantaneous frequency and amplitude in the frequency domain as well as the quantity in the temporal domain at each measuring point of IMFs can be obtained and further employed in the subsequent data analysis. Note that the marginal spectrum, which offers amplitude variations versus frequency over a data span, is utilised to determine significant frequency bands via enhanced amplitudes (see details in Huang et al., 1998). 
Table 2. Basic information for the major earthquakes $(M>6)$ during the entire study period from (1 August 1997 to 31 December 2009$)$.

\begin{tabular}{llrrrr}
\hline $\begin{array}{l}\text { Parameters } \\
\text { Earthquake }\end{array}$ & Time & $\begin{array}{r}\text { Longitude } \\
\left({ }^{\circ} \mathrm{E}\right)\end{array}$ & $\begin{array}{r}\text { Latitude } \\
\left({ }^{\circ} \mathrm{N}\right)\end{array}$ & $\begin{array}{r}\text { Depth } \\
(\mathrm{km})\end{array}$ & $\begin{array}{r}\text { Magnitude } \\
(M)\end{array}$ \\
\hline Rei-Li (R) & $17 / 07 / 199804: 51: 14.96$ & 120.663 & 23.503 & 3 & 6.2 \\
Chi-Chi (C) & $20 / 09 / 199917: 47: 15.85$ & 120.816 & 23.853 & 8 & 7.6 \\
Chia-Yi & $22 / 10 / 199902: 18: 56.90$ & 120.423 & 23.517 & 17 & 6.4 \\
Ming-Jian (M) & $05 / 11 / 200909: 32: 57.66$ & 120.719 & 23.789 & 24 & 6.2 \\
\hline
\end{tabular}

Note: the Chia-Yi earthquake is excluded from the study due to its proximity with Chi-Chi earthquake and severe interference in data processing from groundwater level recovery.

\section{Long-term variations of groundwater level in central Taiwan}

It is well known that precipitation is highly related with climatic changes and is the major factor dominating the variations of groundwater levels. Before retrieving earthquakerelated signals from groundwater levels, long-term climate changes (3-5 yr in period; Newman et al., 2003) were considered first. Figure 2 shows variations in groundwater level at the $\mathrm{HH}, \mathrm{HT}$ and $\mathrm{TH}$ stations and records in precipitation at the Yunlin station $\left(120.476^{\circ} \mathrm{E}, 23.636^{\circ} \mathrm{N}\right)$ between 1 August 1997 and 31 December 2009. Precipitation effects on groundwater level can be viewed as two distinct features during this $12.5 \mathrm{yr}$ period (i.e., between 1 August 1997 and 31 December 2009). The first feature, which comprises many short (3-5 yr) cycles lying on the generally decreasing trend in the first half (before 2004; i.e., $\sim 1500$ days from the ChiChi earthquake) and then a rising tendency in the latter half, yields an agreement between $1 \mathrm{yr}$ running average in annual precipitation (red line) and groundwater levels (blue line) at the HH, HT and TH sites. Studies of Huang et al. (2011) and WRA (2010) indicate that this down-and-rise feature is a faithful reflection of regional climatic and/or hydrological changes for the last decade in Taiwan.

The second one is apparent annual cycles that dominate in groundwater levels, particularly for those of the $\mathrm{HH}$ and TH sites. Annual cycles of the groundwater levels in Taiwan are caused by the apparent shift between wet and dry seasons in one year. For stations located relatively far away from recharge areas, their annual changes in the time-series data are comparatively weak, such as the HT shown in the plot. It is worth mentioning that an unusual drop can be clearly identified from records at $78 \%(=42 / 54)$ stations (including HT, HH and TH) about 250 days prior to the Chi-Chi earthquake. The HT site had this obviously unusual drop standing out in the temporal domain due to weak annual changes. By contrast, for sites of $\mathrm{HH}$ and $\mathrm{TH}$, the abnormal drops would be masked by in-phase annual variations in groundwater levels in the time-series record. This feature vividly illustrates the primary drawbacks in retrieving the abnormal drops of groundwater levels via the temporal records.

\section{Removal of short-term effects on groundwater level}

Since the unusual drop with duration of $\sim 250$ days should not relate with long-term climatic changes, variations of atmospheric pressure, Earth's tides, precipitation and human extraction, which are considered to be the major factors affecting groundwater levels, (Bredehoeft, 1967; Van der Kamp and Gale, 1983; Narasimhan et al., 1984; Roeloffs, 1988) are further taken into account. We examine these shortterm effects (i.e., atmospheric pressure, Earth's tides, precipitation and human extraction) using groundwater data with a time span between 1 August 1997 and 31 December 2000 to adequately cover the unusual drop. The upper panel in Fig. 3 illustrates the variations of air pressure measured at the southern site $\left(120.424^{\circ} \mathrm{E}, 23.498^{\circ} \mathrm{N}\right.$; the location can be viewed in Fig. 1) of the study area. It is clear that annual fluctuations are dominant in the air pressure records. Low and high air pressures were regularly observed in summer and winter seasons, respectively. Effects of the atmospheric pressure on the groundwater level ranging between $-0.2 \mathrm{~m}$ and $0.2 \mathrm{~m}$ were then utilised in data correction (Rojstaczer, 1988; Inkenbrandt et al., 2005). The Earth's tides with the frequencies of 1 and 2 day $^{-1}$ could be easily eliminated while hourly data were down-sampled as a daily record. Corrected groundwater level data could, thus, be obtained while responses of air pressure and the Earth's tide were removed.

The middle and bottom plots in Fig. 3 present variations in corrected groundwater data at the HH, HT, Honglung (HR) and Tienwei (TW) sites (see Fig. 1 for locations) and precipitation at the Yunlin station $\left(120.476^{\circ} \mathrm{E}, 23.636^{\circ} \mathrm{N}\right)$ from 1 August 1997 to 31 December 2000, respectively ( -800 days to +450 days relative to the Chi-Chi earthquake). Unusual decreases of approximately $2-4 \mathrm{~m}$ in corrected water levels can be clearly identified in these groundwater wells about 150 days before the Chi-Chi earthquake. We further examined records of 54 monitoring wells in the Choshuichi Alluvial Fan and found that similar patterns of unusual decrease are observed at $78 \%$ wells, primarily distributed near the Chelungpu fault (see Fig. 1). Unusual decreases by artificial water pumping can be eliminated as the cause because temporal duration of these anomalous decreases exceeded 200 days (from -250 to -50 day prior to the Chi-Chi earthquake) and the anomalous wells are widely distributed 

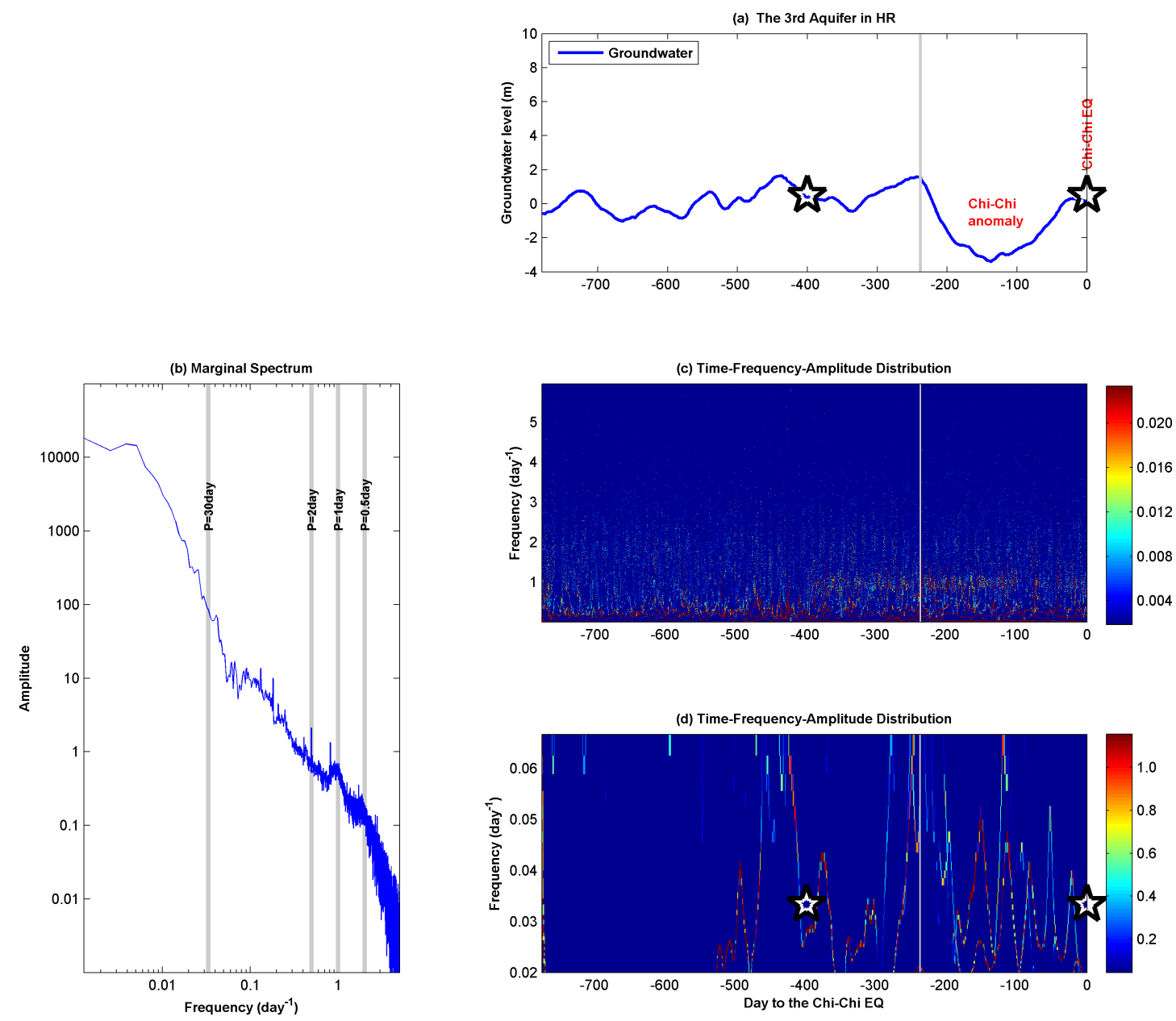

Fig. 4. (a) Temporal variations, (b) the marginal spectrum of the groundwater levels, (c) the time-frequency-amplitude distribution and (d) the partial amplification of the time-frequency-amplitude distribution before the Chi-Chi earthquake at the HR station. Vertical grey lines in (a), (c) and (d) reveal the beginning of unusual decrease anomalies associated with the Chi-Chi earthquake. The black stars at about -424 and 0 day to the Chi-Chi earthquake denote the Rei-Li and Chi-Chi events, respectively.

in most areas of the Choshuichi Alluvial fan. Drought can be excluded as well, because the annual precipitation in 1999 accounted to $80 \%$ of Taiwan's annual average. The annual precipitation in $1999(1980.5 \mathrm{~mm})$ is higher than that in 2000 $(1397.5 \mathrm{~mm})$ and lower than $1998(2310.5 \mathrm{~mm})$. If drought had played a major factor, the same pattern of low groundwater levels would have been repeated in 2000 . Thus, possibility of the unusual drops in the Choshuichi Alluvial Fan can be ascribed to the Chi-Chi earthquake in both temporal and spatial domains, after factors from the long-term (i.e., climatic changes and annual cycles) and short-term effects have been removed. We further survey the $12.5 \mathrm{yr}$ time-series data (see Fig. 2); however, no similar drop-like variations can be repeatedly observed for other two major earthquakes (i.e., the $\mathrm{R}$ and $\mathrm{M}$ earthquakes) in the temporal domain.

\section{Frequency characteristics of groundwater level drops and 12.5 yr survey}

Here, HHT was applied on records of groundwater level to expose possible frequency characteristics of the unusual drop in the frequency domain. The groundwater level at the HR site was utilised as an example to determine anomalous frequency bands associated with the Chi-Chi earthquake via HHT. Figure 4a shows the time-series records of airpressure-free groundwater level variations at the HR station covering about 800 days (i.e., starting from 1 August 1997) before the Chi-Chi earthquake. The unusual drop can be readily viewed before the Chi-Chi (C) earthquake in the temporal domain, but not shown before the Rei-Li (R) earthquake, probably due to earthquake-related signals lost in intense annual variations. When the data of groundwater levels at HR from 1 August 1997 to 19 September 1999 were transferred into the frequency domain, the marginal spectrum 

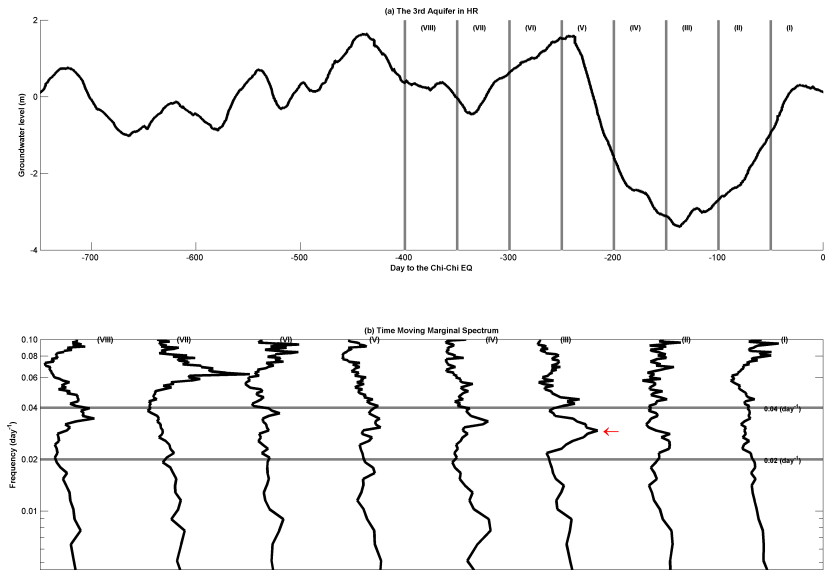

Fig. 5. Changes of the marginal spectrum derived from the 50 day temporal moving window for the HR station. The red arrow denotes the significantly enhanced amplitude at the III phase.

reveals obvious amplitude distribution at periods of 1 and 0.5 day (Fig. 4b) that is obviously affected by the Earth's tides and is in agreement with previous studies (Quilty and Roeloffs, 1991).

Note that the time-frequency-amplitude distribution would be seriously damaged if co-seismic data with step changes are analysed by using the Fourier and/or wavelet transform due to enhanced amplitude distribution at wide frequency bands. When the time-frequency-amplitude distribution of the HR site was examined in depth (Fig. 4c), the phenomenon essentially disappeared in HHT analysis. This suggests that the effect of co-seismic changes caused by other earthquakes is either very small or can be effectively mitigated in the HHT process (also see Chen et al., 2010b). It also suggests that amplitude enhancements at the associated frequency band before the $\mathrm{R}$ and $\mathrm{C}$ earthquakes are very apparent in Fig. 4c. Figure $4 \mathrm{~d}$ demonstrates that the time-frequency-amplitude distribution ranged at the frequency between $0.02 \mathrm{day}^{-1}$ and 0.07 day $^{-1}$ (i.e., with periods from 14 to 50 days) from the record covering $\sim 520$ days before the Chi-Chi earthquake. It is of interest that amplitudes at the frequency band between 0.02 day $^{-1}$ and 0.04 day $^{-1}$ seem to be particularly enhanced before the $\mathrm{R}$ and $\mathrm{C}$ earthquakes.

To clearly identify frequency characteristics associated with the Chi-Chi earthquake, the groundwater level at the HR site between 400 and 1 days prior to the earthquake is separated into 8 phases (i.e., I to VIII in Fig. 5a) using a timesliding window of 50 days. Marginal spectrums were computed from transferred data in the frequency domain within each phase to survey associated frequency bands via enhanced amplitude (Fig. 5b). In general, the amplitudes of the marginal spectrums are inversely proportional to frequency, except for (VII) for unknown reasons. Regarding the unusual groundwater level decrease in the temporal domain from (III) to (V), enhanced amplitude at the frequency between

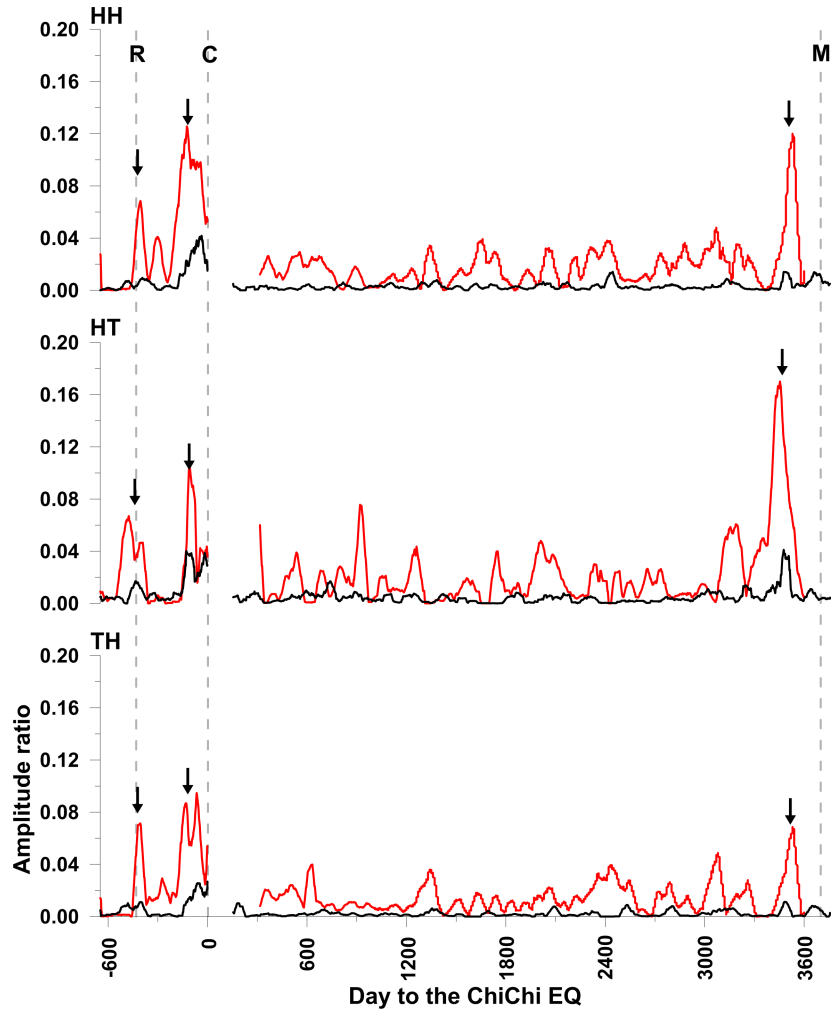

Fig. 6. The amplitude ratios of groundwater levels at HH, HT and TH stations from 1 August 1997 to 31 December 2009. The red (black) line denotes the amplitude ratios deduced from the frequency band between 0.02 day $^{-1}$ and 0.04 day $^{-1}\left(0.05\right.$ day $^{-1}$ and 0.04 day $\left.^{-1}\right)$. The vertical dash lines indicate occurrence dates of the $\mathrm{R}, \mathrm{C}$ and $\mathrm{M}$ earthquakes. Meanwhile, the arrows show the enhanced amplitude ratios at the frequency band between 0.02 day $^{-1}$ and 0.04 day $^{-1}$ associated with these three earthquakes.

0.02 day $^{-1}$ and 0.04 day $^{-1}$ is very evident, especially in the phase of (III), that is, about 150 days before the occurrence of the Chi-Chi earthquake. Note that the determined frequency band is particularly isolated from influences of the climatic change (0.2-0.3 $\mathrm{yr}^{-1}$, also see Newman et al., 2003), annual cycles $\left(1 \mathrm{yr}^{-1}\right)$, atmospheric pressure $\left(1 \mathrm{yr}^{-1}\right)$ and Earth's tides $\left(1\right.$ and $\left.0.5 \mathrm{day}^{-1}\right)$. This is consistent with observation in the temporal domain discussed earlier.

To examine whether the feature of the enhanced amplitude at a certain frequency band (i.e., between 0.02 day $^{-1}$ and 0.04 day $^{-1}$ ) can be employed as a common index associated with earthquakes, long-term groundwater data from 1 August 1997 to 31 December 2009 at the HH, HT and TH sites were all transferred into the frequency domain via HHT. Data (from 1 August 1997 to 31 December 2009; i.e., from -780 days to +3755 days relative to the Chi-Chi earthquake) were separated into two time-series slots, 1 August 1997-19 September 1999 and 1 January 2000-31 December 2009, to avoid the disturbance of intense co-seismic signals and subsequent groundwater recovery after the Chi-Chi 

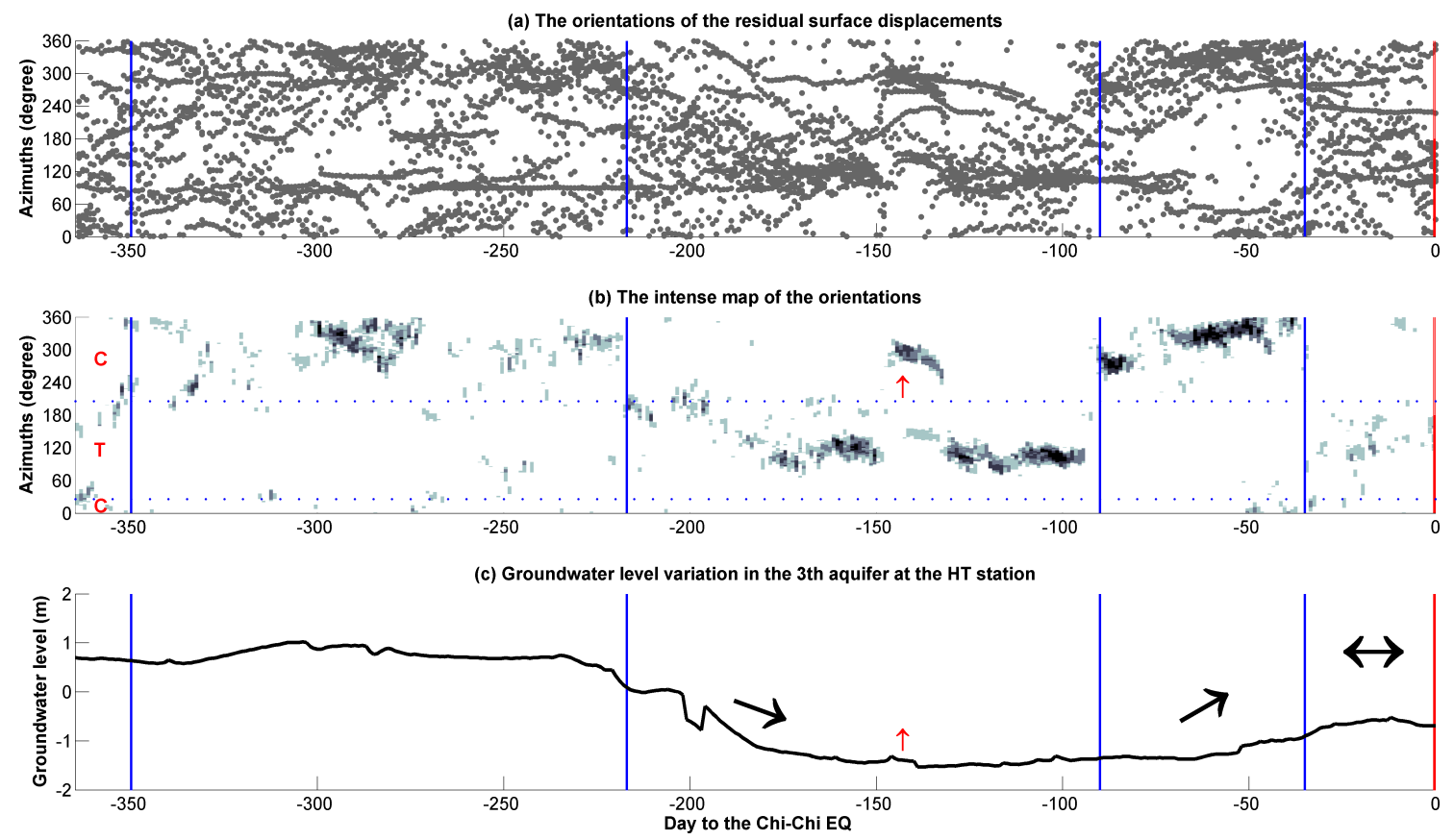

Fig. 7. (a) The orientations of the residual surface displacements at 15 GPS stations during the one-year span before the Chi-Chi earthquake. (b) The intense map of the orientations for the same period from (a). Red letters of $\mathrm{C}$ and $\mathrm{T}$ on the left indicate compression and tension domains, respectively. Blue vertical lines are divides of compression and tension domains, and red vertical line is the occurrence day of Chi-Chi earthquake. (c) Variations of groundwater level at the HT station during the one-year span before the Chi-Chi earthquake.

earthquake. These two separated data sets were transferred into the frequency domain using HHT, respectively. Amplitude ratios were computed by using integrated amplitude at the frequency band between 0.02 day $^{-1}$ and 0.04 day $^{-1}$ relative to total amplitude (at the entire frequency band) within a 50 day moving window. The analytical process of amplitude ratios was thus normalized in order to mitigate effects from the total energy in time-shifting process.

Figure 6 shows variations in the amplitude ratios over time for the groundwater level records of three monitoring wells (HH, HT and TH). During the study period (1 August 199731 December 2009), three significantly enhanced peaks before the occurrences of three major earthquakes (the R, C and $\mathrm{M}$ earthquakes; see details in Table 2) can be found from these $12.5 \mathrm{yr}$ data with much reduced annual cycles (also comparing with Fig. 2), even though these sites are widely distributed across the Choshuichi Alluvial Fan. The results clearly suggest that the enhanced amplitudes at the frequency between 0.02 day $^{-1}$ and 0.04 day $^{-1}$ derived from corrected groundwater level variations show a very promising herald in appreciation of immense accumulating strain during the earthquake incubation period, because these peaks all appear right before the major earthquakes (magnitudes larger than 6). Note that a step change on groundwater level at the HT site (middle panel) happened a few months before the M earthquake. The enhanced amplitude at the HT site before the $\mathrm{M}$ earthquake could be caused by both the step change in groundwater levels and earthquake-related variations from a small-magnitude earthquake. Thus, the frequency between 0.02 day $^{-1}$ and 0.04 day $^{-1}$ can serve as the most relevant target to pursue earthquake-related signals in the study. On the other hand, the amplitude at frequency between 0.04 day $^{-1}$ and 0.05 day $^{-1}$ was also enhanced at the (VII) phase earlier than abnormal drop in the normal stage (also see Fig. 5), but cannot be repeatedly observed for the $\mathrm{R}$ and $\mathrm{M}$ earthquakes (Fig. 6). The frequency between $0.04 \mathrm{day}^{-1}$ and $0.05 \mathrm{day}^{-1}$ is, thus, eliminated from concern for earthquake-related characteristics.

In short, Fig. 6 demonstrates the advantage of transformation from the temporal domain into the frequency domain. For the $\mathrm{R}$ and $\mathrm{M}$ earthquakes, none of these three sites shows any pre-earthquake signal in their corrected groundwater records in the temporal domain (Fig. 2). Earthquakerelated signals in groundwater levels are often difficult to distinguish from long-term records in the temporal domain, but can be identified in the frequency domain using the transferred time-frequency-amplitude distribution and/or the marginal spectrums. This analysis plainly illustrates the inherited weakness of groundwater level records in the temporal domain, especially for those with large annual fluctuations. The method proposed in this study is able to recuperate earthquake-related anomalous changes after the domain transformation. 
Table 3. Locations of the 15 GPS stations in Taiwan.

\begin{tabular}{lrr}
\hline Code & Latitude $\left({ }^{\circ} \mathrm{N}\right)$ & Longitude $\left({ }^{\circ} \mathrm{E}\right)$ \\
\hline BANC & 24.998 & 121.442 \\
CHEN & 23.097 & 121.374 \\
CHIA & 23.496 & 120.433 \\
FIVE & 25.071 & 121.781 \\
FLNM & 23.746 & 121.453 \\
HENC & 22.004 & 120.746 \\
HSIN & 24.828 & 121.014 \\
HUAL & 23.975 & 121.614 \\
ILAN & 24.764 & 121.757 \\
KDNM & 21.949 & 120.782 \\
PKGM & 23.580 & 120.305 \\
SANI & 24.414 & 120.769 \\
SUNM & 23.881 & 120.908 \\
TMAM & 22.616 & 121.007 \\
YMSM & 25.166 & 121.574 \\
\hline
\end{tabular}

\section{Discussion and conclusions}

Since high-magnitude earthquake occurrence is resulted from large-scale stress accumulation and plate movements, significant surface and subsurface displacements are expected (Scholz et al., 1973; Wang and Manga, 2010). For the surface part, Chen et al. (2011) reported that the horizontal orientations of the residual displacements, which are deduced from surface displacement data via the band-pass filter of $0.05-0.0067$ day $^{-1}$ (i.e., $20-150$ days in period) to mitigate effects of long-term plate movements, short-term noise and frequency-dependent signals, are generally random in order. The orientations of the residual displacements would be aligned toward the direction of the maximum horizontal compressive stress of thrust earthquakes once earthquakerelated stress disturbs on crust. The orientations turn to the inverse direction after thrust earthquake occurrence that agrees with the seismic rebound theory (Reid, 1910) and parameters of focal mechanisms (for more detail see Chen et al., 2011, 2013). For the subsurface part, groundwater level variation is a promising candidate because it is very sensitive to the pressure change from stress accumulation in favourable sites (Wang and Manga, 2010). In this study, the Chi-Chi earthquake is taken as an example to examine relationships between the horizontal orientations of the residual displacements on surface and unusual groundwater level changes in subsurface due to earthquake-related stress disturbance.

The horizontal orientations of the residual displacements before the Chi-Chi earthquake are retrieved from the 15 GPS (global positioning system) stations (Fig. 1; Table 3) strictly following the guides and analytical method proposed in Chen et al. (2011). Figure 7a shows the time-series horizontal orientations within the one-year time span (i.e., between -365 to -1 days) prior to the Chi-Chi earthquake. The significant tendency of the orientations along time can be deduced via a time-orientation moving-window and expressed in Fig. 7b. It is obvious that the tendency formed by similar orientations of residual displacements at the stations mainly ranged at $300^{\circ}$ (northwestern direction in Fig. 1) about -350 to -220 days to the Chi-Chi earthquake. The tendency rapidly switched to $120^{\circ}$ (southeastern direction in Fig. 1) at approximately -220 days and maintained at the low stage $\left(\sim 120^{\circ}\right)$ to -95 days, except for a 20 day short period (i.e., from -150 to -130 days), in which the orientations returned to approximately $300^{\circ}$. The orientations on the tendency are changed from $120^{\circ}$ to $300^{\circ}$ again during -95 to -35 days. Starting from -35 days to the -1 day prior to the earthquake, the orientations became random in order that is consistent with the observation of the previous study (Chen et al., 2011) and infers earthquake-related stress disturbance reaching to the threshold of fault rupture in the last stage.

When relative locations between the GPS stations and Chelungpu fault activated by the Chi-Chi earthquake are jointly considered, the orientation of about $300^{\circ}$ (NW direction) suggests a compression loading on the crust in Taiwan due to the moving of the residual displacements toward the earthquake fault, and the orientation of $120^{\circ}$ (SE direction) indicates the tension state (i.e., moving away from the earthquake fault). As the compression loaded before the earthquake, the rising of groundwater level was concurrently observed in the same period. The same parallelism was also perceived in subsequent tension mode of surface loading with significant decreasing of groundwater level (Fig. 7b and c). Regarding to the period of approximately -35 days to -1 day before the earthquake, neither compression nor tension can be determined from greatly random orientations. In this stage, indistinct earthquake-related stress pattern corresponded to a very smooth shape in groundwater level. Although the physical mechanism is still not fully understood, the agreement between time-series changes in groundwater level and surface deformation determined using the residual displacements in the frequency domain strongly suggests that large-scale and earthquake-related stress disturbances dominate in both records of groundwater level and surface displacements during one-year span before the Chi-Chi earthquake.

The debate regarding pre-earthquake groundwater anomalies in previous studies is primarily due to the limited number of observation wells over a wide area (Biagi et al., 2001) and the anomalous patterns for different strong earthquakes, which are often very hard to repeat and define. In this study, we have shown that an anomalous decrease in groundwater levels was observed in effect-corrected records at the $78 \%(=42 / 54)$ of the wells widely distributed across the Choshuichi Alluvial Fan nearby the Chelungpu fault a few months before the Chi-Chi earthquake. Thus, groundwater level has the potential to reflect the tectonic stress accumulation prior to the occurrence of the Chi-Chi earthquake if the monitoring wells are densely distributed and close to the 
epicentre, as demonstrated in Fig. 6. Apart from the large signals, some relatively-small peaks of enhanced amplitude ratios can be observed at HT and/or TH in Fig. 6, but cannot be simultaneously observed at the other two stations, implying that they are local and small-magnitude events resulting in limited peaks. The tendency distribution plot, which is determined by the orientations retrieved from the 15 GPS stations and is shown in Fig. 7b, displays a good consistency with the rise and fall of the groundwater level. This suggests that groundwater level and surface displacement anomalies from large and significant earthquakes should be simultaneously observable at multiple stations. By contrast, changes in groundwater level at the residual $22 \%(=100-78 \%)$ stations yield inconsistent relationships with surface displacements. The inconsistent results may be caused by local factors in suppression of earthquake-related signals (Wang et al., 2001; Wang and Manga, 2010). Thus, it is highly risky to assess pre-earthquake anomalous phenomena using only few and isolated stations.

Critical earthquake-related signals are often hidden behind substantial and common effects with various frequencies (such as precipitation, diurnal and semi-diurnal variations in groundwater levels). For the stand-out of anomalous patterns, our study shows that it is difficult to retrieve and/or understand these vital earthquake-related signals without removing these common effects via an adequate filter. The seismo-groundwater anomalies in the Choshuichi Alluvial Fan in Taiwan could be clearly identified for all three strong earthquakes $(M>6)$ because amplitudes at the frequency band between 0.02 day $^{-1}$ and 0.04 day $^{-1}$ were consistently enhanced in groundwater level records of many monitoring wells in the frequency domain. In short, this new method sheds light on the precursory-seeking research of strong earthquakes, but needs further work to refine the technique and test its applicability for the forthcoming strong earthquakes. Naturally, the method presented in this work has also its limitation and prerequisite. For example, an adequately dense monitoring network has to be established first. Another one is that it cannot be applied to the earthquake right after a strong one, such in the case of Chia-Yi earthquake in this study. Nonetheless, if this method is well integrated with other geophysical observations, such as geomagnetic anomalies (Chen et al., 2010c) and crustal displacements (Chen et al., 2011, 2013), variations in groundwater levels and electromagnetic anomalies could be quantified and/or modelled by using volume changes via possible physical mechanisms. These integrated results will be highly promising to understanding underlying mechanisms of major earthquakes and to build a strong earthquake forecast system in the future.

Acknowledgements. Constructive comments from reviewers and editor are greatly appreciated for improving the manuscript. The authors would like to thank Central Weather Bureau of Taiwan for the GPS data and the earthquake catalogue in the analyses of this study and the National Science Council of the Republic of China for financially supporting this research under Contracts No. NSC 100-2116-M-001-027-MY3 and NSC 100-2116-M-001-005.

Edited by: Y. Fan

\section{References}

Biagi, P. F., Piccolo, R., Ermini, A., Fujinawa, Y., Kingsley, S. P., Khatkevich, Y. M., and Gordeev, E. I.: Hydrogeochemical precursors of strong earthquakes in Kamchatka: further analysis, Nat. Hazards Earth Syst. Sci., 1, 9-14, doi:10.5194/nhess-1-92001, 2001.

Bracewell, R. N.: The Fourier Transform and Its Applications, 3rd Edn., McGraw-Hill, Boston, Mass, 624 pp., 2000.

Bredehoeft, J. D.: Response of well-aquifer systems to Earth tides, J. Geophys. Res., 72, 3075-3087, 1967.

Brodsky, E. E., Roeloffs, E., Woodcock, E., Gall, I., and Manga, M.: A mechanism for sustained groundwater pressure changes induced by distant earthquakes, J. Geophys. Res., 108, 2390, doi:10.1029/2002JB002321, 2003.

Chen, C. H., Wang, C. H., Hsu, Y. J., Yu, S. B., and Kuo, L. C.: Correlation between groundwater level and altitude variations in land subsidence area of the Choshuichi Alluvial Fan, Taiwan, Eng. Geol., 115, 122-131, doi:10.1016/j.enggeo.2010.05.011, 2010a.

Chen, C. H., Wang, C. H., Liu, J. Y., Liu, C., Liang, W. T., Yen, H. Y., Yeh, Y. H., Chia, Y. P., and Wang, Y.: Identification of earthquake signals from groundwater level records using HHT method, Geophys. J. Int., 180, 1231-1241, doi:10.1111/j.1365246X.2009.04473.x, 2010b.

Chen, C. H., Liu, J. Y., Lin, P. Y., Yen, H. Y., Hattori, K., Liang, W. T., Chen, Y. I., Yeh, Y. H., and Zeng, X.: Pre-seismic Geomagnetic Anomaly and Earthquake Location, Tectonophysics, 489, 240-247, doi:10.1016/j.tecto.2010.04.018, 2010c.

Chen, C. H., Yeh, T. K., Liu, J. Y., Wang, C. H., Wen, S., Yen, H. Y., and Chang, S. H.: Surface Deformation and Seismic Rebound: implications and applications, Surv. Geophys., 32, 291313, doi:10.1007/s10712-011-9117-3, 2011.

Chen, C. H., Wen, S., Yeh, T. K., Wang, C. H., Yen, H. Y., Liu, J. Y., Hobara, Y., and Han, P.: Observation of surface displacements from GPS analyses before and after the Jiashian earthquake $(M=6.4)$ in Taiwan, J. Asian Earth Sci., 62, 662-671, doi:10.1016/j.jseaes.2012.11.016, 2013.

Chen, W. F. and Yuan, P. A.: Preliminary study on sedimentary environments of Choshui fan-delta, Journal of the Geological Society of China, 42, 269-288, 1999.

Chia, Y., Wang, Y. S., Chiu, J. J., and Liu, C. W.: Changes of groundwater level due to the 1999 Chi-Chi earthquake in the Choshui River Alluvial Fan in Taiwan, B. Seismol. Soc. Am., 91, 1062-1068, 2001.

Daubechies, I.: The wavelet transform time-frequency localization and signal analysis, IEEE Trans. Inform. Theory, 36, 961-1004, 1990.

Ho, C. S.: An introduction to the geology of Taiwan, 2nd Edn., Central Geological Survey, The Ministry of Economic Affairs, Taipei, 192 pp., 1988.

Hsu, S. K.: Plan for a groundwater monitoring network in Taiwan, Hydrogeol. J., 6, 405-415, 1998. 
Huang, H. H., Wu, I. C., Chou, C., Chen, C. T., Chen, Y. M., and Lu, M. M.: Taiwan Climate Change Scientific Report, National Science Council (NSC), Taipei, Taiwan, Republic of China, 57 pp., 2011 (in Chinese).

Huang, N. E. and Wu, Z.: A review on Hilbert-Huang transform: method and its applications to geophysical studies, Rev. Geophys., 46, RG2006, doi:10.1029/2007RG000228, 2008.

Huang, N. E., Shen, Z., Long, S. R., Wu, M. C., Shih, H. H., Zheng, Q., Yen, N. C., Tung, C. C., and Liu, H. H.: The empirical mode decomposition and the Hilbert spectrum for nonlinear and nonstationary time series analysis, P. R. Soc. Lond. Ser. A, 454, 903995, 1998.

Huang, N. E., Shen, Z., Long, S. R., Shen, S. S. P., Hsu, N. H., Xiong, D., Qu, W., and Gloersen, P.: On the establishment of a confidence limit for the empirical mode decomposition and Hilbert spectral analysis, P. R. Soc. Lond. Ser. A, 459, 23172345, 2003.

Igarashi, G. and Wakita, H.: Tidal responses and earthquake-related changes in the water level of deep wells, J. Geophys. Res., 96, 4269-4278, 1991.

Igarashi, G. and Wakita, H.: Geochemical and hydrological observations for earthquake prediction in Japan, J. Phys. Earth, 43, 585-598, 1995.

Inkenbrandt, P. C., Doss, P. K., Pickett, T. J., and Brown, R. J.: Barometric and Earth Tide Induced Water-Level Changes in the Inglefield Sandstone, Southwestern Indiana, Proc. Ind. Acad. of Sciences, 114, 1-8, 2005.

Kingsley, S. P., Biagi, P. E., Piccolo, R., Capozzi, V., Ermini, A., Khatkevich, Y. M., and Gordeev, E. I.: Hydrogeochemical precursors of strong earthquakes: a realistic possibility in Kamchatka, Phys. Chem. Earth., 26, 769-774, 2001.

Liu, C. H. and Huang, C. T.: Taiwan land subsidence caused by groundwater over drafting, J. Civ. Hydraul. Eng., 29, 47-57, 2002.

Ma, K. F., Lee, C. T., and Tsai, Y. B.: The Chi-Chi, Taiwan earthquake: large surface displacements on an inland thrust fault, EOS, 80, 605-611, 1999.

Narasimhan, T. N., Kanehiro, B. Y., and Witherspoon, P. A.: Interpretation of Earth tide response of three deep, confined aquifer, J. Geophys. Res., 89, 1913-1924, 1984.

Newman, M., Compo, G. P., and Alexander, M. A.: ENSO-forced variability of the Pacific decadal oscillation, J. Climate, 16, 3853-3857, 2003.

Quilty, E. G. and Roeloffs, E. A.: Removal of barometric pressure response from water level data, J. Geophys. Res., 96, 1020910218, 1991.
Quilty, E. G. and Roeloffs, E. A.: Water level changes in response to the December 20, 1994 M4.7 earthquake near Parkfield, California, B. Seismol. Soc. Am., 87, 310-317, 1997.

Reid, H. F.: The mechanics of the earthquake, in: The California Earthquake of April 18, 1906, Report of the State Earthquake Investigation Commission, Vol. 2 Washington, DC: Carnegie Institution, 1-192, 1910.

Roeloffs, E. A.: Hydrologic precursors to earthquakes: a review, Pure Appl. Geophys., 126, 177-206, 1988.

Roeloffs, E. A.: Persistent water level changes in a well near Parkfield, California, due to local and distant earthquakes, J. Geophys. Res., 93, 13619-13634, 1998.

Rojstaczer, S.: Determination of fluid flow properties from the response of water levels in wells to atmospheric loading, Water Resour. Res., 24, 1927-1938, 1988.

Scholz, C. H., Sykes, L. R., and Aggarwal, Y. P.: Earthquake Prediction - Physical Basis, Science, 181, 803-810, 1973.

Van Der Kamp, G. and Gale, J. E.: Theory of Earth tide and barometric effects in porous formations with compressible grains, Water Resour. Res., 19, 538-544, 1983.

Wang, C. H.: The Impacts of Climate Change on the Groundwater Environment of Taiwan: Retrospective and Prospective Views, Central Geological Survey, MOEA, Taipei, Taiwan, ROC, Special Publication, 18, 239-255, 2007 (in Chinese with English abstract).

Wang, C. H., Wang, C., Kuo, C. H., and Chen, W. F.: Some isotopic and hydrological changes associated with the $1999(\mathrm{Mw}=7.5)$ Chi-Chi Earthquake, Taiwan, Island Arc, 14, 37-54, 2005.

Wang, C. Y. and Manga, M.: Earthquakes and Water. Lecture Notes in Earth Sciences, 114, Springer, 225 pp., 2010.

Wang, C.-Y., Cheng, L. H., Chin, C. V., and Yu, S. B.: Coseismic hydrologic response of an alluvial fan to the 1999 Chi-Chi earthquake, Taiwan, Geology, 29, 831-834, 2001.

WRA (Water Resources Agency): Report of the Monitoring, Investigating and Analyzing of Land Subsidence in Taiwan (1/4), Ministry of Economic Affairs, Executive Yuan, Taipei, Taiwan, 2001 (in Chinese).

WRA: Hydrological Year Book of Taiwan, Republic of China, Ministry of Economic Affairs, Taipei, Taiwan, 2010 (in Chinese).

WRB (Water Resource Bureau): Summary Report of Groundwater Monitoring Network Plan in Taiwan, Phase I (1992-1998). Ministry of Economic Affairs, Taiwan, 364 pp., 1999 (in Chinese).

Yen, H. Y., Chen, C. H., Yeh, Y. H., Liu, J. Y., Lin, C. R., and Tsai, Y. B.: Geomagnetic fluctuations during the 1999 Chi-Chi earthquake in Taiwan, Earth Planets Space, 56, 39-45, 2004. 